\title{
Renewable Energy: technology, economics and environment
}

\author{
Martin Kaltschmitt, Wolfgang Streicher and Andreas Wiese \\ New York: Springer, Berlin Heidelberg
}

Reviewed by Reviewed by Ram Karan Singh

Resources, Energy, and Development 5(1): 65-66

Energy is the mainstay of the current industrial society. The energy sources on which the worlds' entire energy infrastructure is based are generally fossil fuels; namely petroleum, coal, natural gases, hydropower, and nuclear energy. However, in the present era where climate change has become imperative for sustainable growth and for combating the effect of global warming, the use of renewable energy has become imperative. It is obvious that renewable energy has become essential if we look at the current trend in increase of the gross energy consumption, with a rate of $1.5 \%$ per year from 1980-99, but by only $1.2 \%$ annually since 1990. The issue of future energy security is taking a central role. The economic crisis in East Asia, which began in the summer of 1997 and continued to deepen into the winter of 1998, extending to Latin America and CIS (Commonwealth of Independent States), was the main cause. In 1999, the world energy consumption grew by $0.6 \%$ driven by an increasing demand in the NAFTA (North American Free Trade Agreement) region, by far the largest energy-consuming region in the world. These issues indicate an urgent need for renewable energy technology intervention at a global scale to meet future energy needs and to maintain sustainable economic growth.
The book, Renewable Energy: Technology, Economics, and Environment by Martin Kaltschmitt, Wolfgang Streitcher, and Andreas Wiese, contains ten chapters. It provides a fairly comprehensive yet condensed treatment of theoretical, technical, economical, and environmental aspects of renewable energy. It discusses all aspects of renewable energy in a simple and comprehensive manner with actual data support and illustrations. Spatial and temporal depiction of resource and technology, both at a global and regional scale, is a unique feature of this book. I strongly feel that the book will cater to the needs of students, teachers, researchers, and policymakers in the area of renewable energy.

The book provides all-inclusive lists of symbols, index, annexure, and references. It is synthesized keeping economical, scientific, and environmental aspects of renewable energy and caters to the need of people in a multidisciplinary environment.

The introduction chapter (chapter 1) outlines and discusses the subject matter of energy system, renewable energies, and economic analysis but does not examine environmental analysis thoroughly. Chapter 2 appraises the energy balance of the earth and then puts forward and explains renewable energy with major focus to solar energy, wind 
energy, hydropower and geothermal energy; but does not cover tidal energy. Chapters 3, 4, 5 , and 6 give a comprehensive coverage of solar energy keeping ecological, economical, and technological aspects of energy source in mind, which makes the book highly solarenergy oriented.

Chapter 7 and 8 deal with wind-energy system and hydropower generation and their technical, environmental, and economical aspects in a highly concise manner.

Chapter 9 delivers a new perspective on energy from ambient air and shallow geothermal energy sources. Lastly, chapter 10 focuses and talks about geothermal energy and its various aspects.
There is a brief coverage on harnessing the energy from tidal waves, especially from thermal gradient, ocean currents, salinity gradients, and water vapour in the form of an annexure (Annexure A). Energetic use of biomass is covered and reported in Annexure B.

The book is indeed a comprehensive text for researchers, teachers, decision-makers, planners, and policy-makers but is not student-friendly (both at undergraduate level and post-graduate levels) as there are no numerically solved problems. The readership may increase globally if such problems were introduced. 